\title{
The 14th EuCheMS international conference on chemistry and the environment (ICCE 2013, Barcelona, june 25-28, 2013)
}

\author{
Santiago V. Luis • Eric Jover
}

Received: 4 June 2014 / Accepted: 10 June 2014 / Published online: 20 June 2014

(C) Springer-Verlag Berlin Heidelberg 2014

Any activity involving the generation, production, manipulation, or use of chemicals either in their pure form or in the form of mixtures, complex mixtures, materials, and composites has an impact on the environment. The promotion of research and public awareness on these issues is one of the main objectives of the Division of Chemistry and the Environment (DCE) of the European Association for Chemical and Molecular Sciences (EuCheMS). International Conference on Chemistry and the Environment (ICCE) conferences are the leading event of the DCE and, being held biannually, represent a unique communication and discussion platform for environmental scientists with emphasis on chemistry. According to this context, the main objectives of ICCE 2013 are to link pioneering research with existing and upcoming environmental issues, to discuss fundamental and applicable aspects related to the fate of chemicals in the environment, and to generate awareness for emerging contaminants.

As could be expected, contributions presented to ICCE 2013 covered a broad range of fields connected to the environmental concerns raised by human activities directly or indirectly related to chemistry and were grouped in several symposia focusing on atmospheric, soil, or water pollution; the identification of emerging

Responsible editor: Philippe Garrigues

S. V. Luis $(\bowtie)$

Department of Inorganic and Organic Chemistry, Supramolecular and Sustainable Chemistry Group, University Jaume I, Avda Sos Baynat s/n, 12071 Castellon, Spain

e-mail: luiss@uji.es

E. Jover

Observatori de la Sostenibilitat d'Andorra, Pl Germandat 7, AD600 St Julia De Loria, Andorra

e-mail: ejoverand@gmail.com pollutants; the understanding of the transformation and fate of contaminants and their (eco)toxicological properties; the modeling of the involved processes; and the development of new approaches for green and sustainable chemistry.

The contributions selected for this monographic issue reflect with clarity this selection of topics, combining the setup of new and more efficient and sensitive analytical methods for pollutants of high concern with the analysis of chemical and toxicological properties of those pollutants, the use of mathematical models for understanding different events associated to pollution with the identification of new compounds of increasing environmental concern, and the study of methodologies for removal of pollutants with those for developing improved chemical processes, compounds, and materials having a much reduced environmental footprint.

In the case of atmospheric pollution, the formation, source apportionment, composition, and effects of particulate matter, with special emphasis on ultrafine particles and organic aerosols; the use of chemical tracers for emission sources; or the acquisition and study of timeresolved chemical data of ambient aerosols are of particular interest. Different atmospheric processes influence the levels, composition, size, surface area, light scattering, and absorption and health impact of particulate pollutants, and all these need to be taken into account. Thus, results from field measurements and laboratory campaigns, as well as modeling, of outdoor, indoor, and personal exposure are required. Humic-like substances (HULIS) are important constituents of organic aerosols and play important roles in absorbing sunlight and as cloud condensation nuclei, and the work by Vione et al. reviews the studies on the possible photochemical pathways to HULIS formation involving, in particular, phenolic compounds arising from biomass burning. Two 
additional papers study the temporal, seasonal, and spatial variation of organic tracers in aerosols. In one case, Madrid and Barcelona were selected as models of highly insolated urban areas of dry and humid atmospheres and the results revealed again the high influence that biomass burning can have in PM1 aerosols. In the second study, two comparable cities, Barcelona and Los Angeles, were studied and multivariate analysis was used for source apportionment of water-soluble organic compounds (WSOCs) in PM1 and PM2.5 filter samples, which allowed distinguishing five consistent WSOC clusters, representing five sources, one biomass burning, and four secondary organic aerosols (SOAs). In the last contribution in this area, PM2.5 filter samples were collected with samplers coupled with a wind select sensor, in order to identify which is the pollutant load due to local sources as compared to long-range transport. Positive matrix factorization (PMF) was used to obtain quantitative information on source contributions from the data obtained.

As can be seen from the former contributions, modeling represents an essential tool for the proper understanding of processes associated to atmospheric pollution. The use of the appropriate mathematical tools and modeling is also a key for the analysis of toxicity and ecotoxicity properties of many individual contaminants and mixtures as is clearly illustrated by some of the contributions here gathered.

Soils and sediments are major recipients of chemical pollution and play a critical role in contaminant exposure to ecosystems, in particular governing their (bio)availability and (bio)degradation. This has been illustrated, for instance, in the work by Wilson et al., who investigated and compared the accumulation of $\mathrm{Sb}$ and $\mathrm{As}$ in food crops growing in soils with mining-derived contamination and tested chemical extractants as predictors of the soil-borne $\mathrm{Sb}$ and As bioavailability to plants and humans. The results showed relative $\mathrm{Sb}$ accumulation in vegetables to be lower than that of As.

It is worth mentioning here that arsenic continues being an important pollutant in soil and water, both in terms of the need of new improved analytical techniques and its effects, and a significant number of communications to ICCE 2013 dealt with this subject as well as some other contributions to this monographic issue.

The subject of water pollution and treatment is also addressed by several contributions. Environmental water quality is affected by pollution from point and diffuse sources, land management practices, and water extraction. Anthropogenic as well as biogenic contaminations represent a serious problem for ecosystems and human health. In this regard, innovative wastewater and drinking water treatment technologies are being developed to both prevent pollution discharge and ensure drinking water quality. Of particular relevance in this field, as indicated by the large number of communications presented, is the use of biotreatments, phytoremediation, and advanced oxidation processes for water treatment, and this is clearly shown in different articles. Thus, the work by Matamoros et al. reviews the current knowledge in the area of biologically based wastewater treatment systems, in particular to remove emerging contaminants, while the work by Carvalho et al. reviews the subject of plantpharmaceutical interactions in a double sense: the effect of those water contaminants in crop plants and the use of phytoremediation in constructed wetlands for removal of such pollutants.

Chemical, biochemical, and physicochemical processes play a very important role in the transformation and fate of pollutants. Metabolites and transformation products can have significantly different (eco)toxicological properties than the original pollutants. This is illustrated in several contributions including the work of Oertel et al. studying the determination of several antibiotics on diverse sewage samples. In the case of clindamycin, an increase for its concentration in the final effluent in comparison to the influent of the sewage treatment plan was observed, which could be associated with a retransformation of its metabolite, clindamycin sulfoxide, as this is the main component detected at the influent. Photochemical processes are critical for many of these transformations, and the contribution by De Laurentiis et al. reviews the effects of climate change on surface water photochemistry. On the other hand, these processes can contribute to the removal of pollutants in contaminated environments and, currently, they are the bases of some processes used in the waste treatment plants (municipal and industrial). In this context, the article presented by Dionysiou et al. is a significant example showing the potential of photocatalytic transformations for the treatment of pharmaceutical drugs, in particular oxytetracycline in this work, in wastewaters.

A great research effort in this area is devoted to the socalled "emerging pollutants." This denomination includes substances such as pharmaceuticals and personal care products, nanomaterials, plasticizers, biocides, perfluorinated compounds, flame retardants, inorganics, etc., which are not included currently in monitoring programs. No doubt, nanomaterials represent one of the hot topics in this field and three different contributions in this monographic issue involve their study. In one case, the development of robust methodologies for their separation at trace levels from natural waters, as illustrated for nanocopper(II) oxide, is presented. The second example studies the presence of nanosilver in drinking water and drinking water sources. 
This is a current important issue as this kind of nanomaterials is being often postulated for disinfection procedures at different levels. The third contribution by Kah et al. analyzes the fate of nanoformulations of pesticides in soils. Besides, many different families of organic compounds can fit under the general definition of emerging pollutants and the analysis of behavior, transformation, and analysis, for instance taking advantage of sorptive extraction devices commercially available, and the removal of organic pollutants described in a variety of contributions in this issue could be easily associated to this field. An example of this category of compounds is fluorochemicals that, as reported by D'Hollander, also represent an environmental concern associated to some industrial activities.

Limiting the generation of waste and pollutants at the origin represents an efficient approach to minimize negative impacts of chemistry into the environment. Green and sustainable chemistry involves developing new tools in fabrication, transport, management, and use of chemicals. One of the examples gathered here describes the development of new photoactive polymeric microparticles being able to act as efficient photocatalysts for different organic transformations and displaying an enhanced compatibility with aqueous environments. Such materials can have applications both in preparative chemistry and for removal of organic contaminants. The second example by Soares et al. reviews the efforts carried out for the development of biodegradable chelating agents that could efficiently substitute traditional compounds such as EDTA and DTPA, broadly used for many different applications, sometimes at a high scale, whose discharge to water courses has negative consequences to the environment.

Although the former contributions to this monographic issue have been classified according to the symposium at which the corresponding communications were presented, a simple and fast analysis of their contents reveals that many of them contain elements that could have allowed their classification in other sections. This illustrates, as mentioned above, one of the central features of the work in the areas covered by the DCE, as is the high level of interdisciplinarity and multidisciplinarity required to provide significant advances in the corresponding areas.

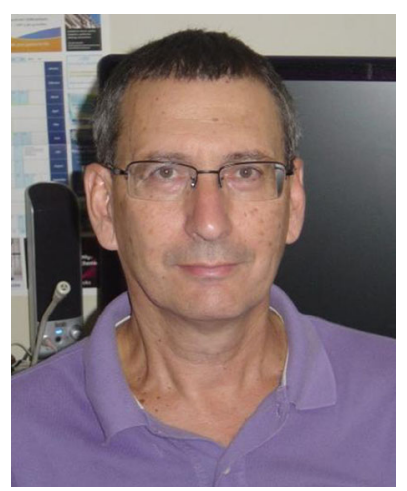

Santiago V. Luis is an Organic Chemist and Director of the Sustainable and Supramolecular Chemistry group at the University Jaume I of Castellón in Spain since 1995. He studied Chemistry at the University of Zaragoza, obtained his $\mathrm{PhD}$ in Organic Chemistry in the University of Valencia and completed a postdoctoral stay at the University of Pittsburgh under the supervision of Prof. J. Rebek, $\mathrm{Jr}$. His research areas involve biomimetic chemistry, new functional polymeric materials, catalysis and new solvents, in particular ionic liquids and supercritical fluids, as tools for Sustainable Chemistry. He has directed more than 40 funded research projects and has published over 250 peer-reviewed research articles in international journals. Co-founder of the Spanish Network for Sustainable Chemistry, he has been the Coordinator of the Spanish Interuniversity Postgraduate Programs (Master and $\mathrm{PhD}$ ) in Sustainable Chemistry for more than 10 years. He represents the Spanish Royal Society of Chemistry at the DCE and was cochair for the ICCE 2013.

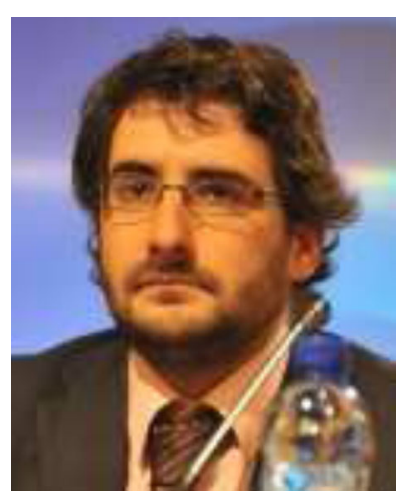

Eric Jover studied Chemistry at the University of Barcelona where he also completed his $\mathrm{PhD}$ in Chemistry. He studied also a MSc in Pollution Control at treatment at the INSA of Toulouse and the course of Expert in Advanced Statistics at the UNED. $\mathrm{He}$ carried out postdoctoral research at the IQAB-CSIC and the University of Barcelona. He is currently consultant for Environmental issues for different public institutions and the Government of Andorra and member of the advisory board of the Waste Thermal Treatment Center in Andorra. Member of the Boards of Directors of the Catalan Society of Chemistry and the Andorran Society of Sciences. He belongs to the Observatory of Sustainability in Andorra. His research interest involve the characterization of complex samples by GCxGC-ToFMS, the use of reclaimed wastewater in agriculture, the determination of organic and organometallic pollutants in environmental and biological samples, paleoclimatic reconstructions, climatology and climate change. He has published over 50 peer-reviewed research articles in international journals. He represents the Catalan Society of Chemistry at the DCE and was co-chair for the ICCE 2013. 